\title{
Supplementary material for Seismic waveform tomography of the Central and Eastern Mediterranean upper mantle
}

\author{
Nienke Blom, Alexey Gokhberg, Andreas Fichtner
}

September 17, 2019

In this Supplementary material, we report the events used in the inversion (Section 1), the adaptations made to the parameters of certain events (Section 2) and the processing applied to raw gradients in the inversion as well as the processing applied to cumulative updates after some sets of iterations (Section 3). Separate to this document, we provide a video of a $3-\mathrm{D}$ visualisation of the final model, as well as the vtk and ParaView files corresponding to this.

\section{List of events used in the inversion}

Table 1 contains all events used in the inversion. Events whose parameters were shifted are included in the table twice: once with the original parameters (from the CMT catalogue, Ekström et al., 2012; Dziewonski et al., 1981, http://www.globalcmt.org) and once with adapted parameters. Original events are marked with a star $(*)$, adapted events are italicised. The final column gives the iterations in which each of the events were used.

The new events that are used to test the final model and which are not used in the inversion are included at the end of the table below a double horizontal line. Letters A-E correspond to the letters A-E in Figure 14 in the manuscript.

\begin{tabular}{|c|c|c|c|c|c|c|}
\hline & Origin time (UTC) & $\begin{array}{l}\text { Latitude } \\
{\left[^{\circ}\right]}\end{array}$ & $\begin{array}{l}\text { Longitude } \\
\left.{ }^{\circ}\right]\end{array}$ & $\begin{array}{l}\text { Depth } \\
{[\mathrm{km}]}\end{array}$ & $\begin{array}{l}\text { Magnitude } \\
{[\mathrm{Mwc}]}\end{array}$ & Iterations \\
\hline event_01 & 2014-05-24 09:25:18 & 40.30 & 25.67 & 12.0 & 6.90 & $0-100$ \\
\hline event_03 & 2000-06-15 21:30:36 & 34.45 & 20.49 & 15.0 & 5.10 & $0-19$ \\
\hline event_04 & 2013-06-16 21:39:07 & 34.22 & 25.19 & 20.0 & 6.10 & $0-100$ \\
\hline event_06 & 2012-10-19 03:35:14 & 32.44 & 31.02 & 29.0 & 5.00 & $0-100$ \\
\hline event_07 & 2010-11-14 23:08:28 & 36.48 & 36.08 & 12.0 & 4.90 & $0-100$ \\
\hline event_08 & 2008-02-15 10:36:21 & 33.27 & 35.32 & 12.1 & 5.10 & $0-100$ \\
\hline event_09 & 2010-11-03 00:57:00 & 43.67 & 20.65 & 13.8 & 5.50 & $0-100$ \\
\hline event_12 & 2000-06-06 02:41:52 & 40.75 & 32.70 & 15.0 & 6.00 & $0-100$ \\
\hline event_14 & 2009-12-29 11:08:56 & 32.56 & 15.04 & 12.0 & 5.00 & $0-100$ \\
\hline event_16 & 2015-10-09 14:39:19 & 40.80 & 36.62 & 17.8 & 5.00 & $0-100$ \\
\hline event_19 & 2012-04-26 22:05:34 & 39.09 & 29.25 & 13.6 & 4.80 & $0-100$ \\
\hline event_24 & 2009-05-24 16:17:53 & 41.17 & 22.79 & 12.8 & 5.30 & $0-100$ \\
\hline event_25 & 2014-11-07 17:13:01 & 38.15 & 22.12 & 13.2 & 5.10 & $0-100$ \\
\hline event_29 & 1998-05-28 18:33:33 & 31.39 & 27.36 & 39.0 & 5.50 & $0-19$ \\
\hline event_31 & 2015-04-15 08:25:15 & 34.72 & 32.36 & 17.9 & 5.30 & $0-100$ \\
\hline event_32 & 2002-09-06 01:21:33 & 38.42 & 13.57 & 15.0 & 5.90 & $0-65$ \\
\hline event_33 $*$ & 2009-04-06 01:32:49 & 42.29 & 13.35 & 12.0 & 6.30 & $0-28$ \\
\hline event_33_shift & 2009-04-06 01:32:46 & 42.29 & 13.35 & 12.0 & 6.30 & $30-100$ \\
\hline event_34 & 2008-02-14 10:09:29 & 36.24 & 21.79 & 20.0 & 6.80 & $0-100$ \\
\hline event_35 & 2009-09-06 21:49:46 & 41.37 & 20.36 & 12.0 & 5.50 & $0-100$ \\
\hline event_36 & 2013-10-12 13:11:56 & 35.37 & 23.37 & 15.0 & 6.80 & $0-100$ \\
\hline event_37 & 2015-11-17 07:10:12 & 38.47 & 20.53 & 15.0 & 6.50 & $0-100$ \\
\hline event_38 * & 2012-06-10 12:44:19 & 36.28 & 29.06 & 28.4 & 6.10 & $0-65$ \\
\hline event_38_shift & 2012-06-10 12:44:19 & 36.34 & 29.00 & 28.4 & 6.10 & $65-100$ \\
\hline event_39 & 2002-02-03 07:11:43 & 38.62 & 31.21 & 15.0 & 6.50 & 0-19 \\
\hline event_40 & 2010-03-08 02:32:37 & 38.82 & 40.04 & 15.1 & 6.10 & $0-100$ \\
\hline event_41 & 2015-06-27 15:34:03 & 28.83 & 34.62 & 28.3 & 5.60 & $0-100$ \\
\hline event_42 & 2012-05-22 00:00:33 & 42.51 & 23.05 & 12.8 & 5.60 & $0-100$ \\
\hline event_43 & 2002-11-01 15:09:09 & 41.80 & 14.88 & 15.0 & 5.70 & $0-85$ \\
\hline
\end{tabular}


Origin time (UTC)

event_44

event_45

event_46

event_47

event_48

event_49

event_50

event_51

event_53

event_54

event_55

event_56

event_57

event_58

event_59

event_61

event_62

event_63

event_64

event_65

event_66

event_67

event_68

event_69

event_70

event_71

event_72

event_73

event_74

event_75

event_76

event_77

event_78

event_79

event_80

event_81

event_82

event_83

event_84

event_85

event_86

event_87

event_88

event_89

event_90

event_91

event_92

event_93

event_94

event_95

event_96

event_97

event_98 *

event_98_shift

event_99

event_100

event_101*
2003-03-29 17:42:21

2004-02-11 08:15:06

2012-05-11 18:48:32

2001-06-25 13:28:52

2008-11-12 14:03:21

2003-07-13 01:48:25

2002-06-24 01:20:42

2011-07-07 19:21:50

2010-11-03 18:13:13

2012-05-20 02:03:56

2009-08-05 07:49:04

2012-03-26 10:35:35

2007-01-21 07:39:01

2012-10-25 23:05:28

2009-11-03 05:25:13

2007-08-31 20:52:45

2016-08-24 02:33:32

2007-11-09 01:43:09

2008-08-03 00:39:19

2005-10-17 05:45:24

2013-01-08 14:16:11

2009-08-21 13:40:01

2013-07-21 01:32:27

2006-05-25 23:14:41

2007-02-03 13:43:25

2008-06-12 00:20:49

2011-05-19 20:39:05

2012-01-27 01:33:25

2005-01-11 04:35:57

2007-05-21 16:39:11

2007-12-20 09:48:32

2011-09-22 03:22:38

2005-06-06 07:41:33

2007-10-29 09:23:19

2015-11-29 00:28:11

2014-08-24 19:43:39

2011-07-25 17:57:22

2012-09-19 09:17:48

2006-10-24 14:00:23

2008-01-06 05:14:23

2014-08-29 03:45:08

2014-04-04 20:08:08

2008-06-18 01:58:45

2007-10-27 05:29:43

2006-10-26 14:28:39

2005-07-10 13:10:15

2005-09-27 00:25:39

2013-06-21 10:34:00

2015-06-09 01:09:06

2007-04-10 10:41:05

2013-07-02 10:45:23

2007-06-29 18:09:15

2013-12-28 15:21:06

2013-12-28 15:21:06

2012-07-09 13:55:00

2016-10-30 06:40:24

2016-08-24 01:36:36
Latitude

[]

42.89

31.62

34.22

37.23

38.92

38.16

36.03

41.94

39.95

44.89

43.42

39.15

39.60

39.88

37.35

36.59

42.68

38.78

39.54

38.21

39.62

41.76

43.48

36.55

35.67

35.28

34.32

35.89

36.84

35.14

39.43

39.68

39.44

36.89

38.82

37.64

40.80

37.28

40.46

36.98

36.46

37.11

37.63

37.70

38.65

42.37

43.18

44.10

38.51

38.55

39.97

39.19

35.82

35.97

35.36

42.75

42.64
Longitude

[]

15.22

35.31

34.17

35.71

35.46

38.90

10.29

7.63

12.89

11.44

28.60

42.20

42.72

15.98

20.19

26.32

13.15

25.66

23.76

26.59

25.61

19.07

13.68

19.91

22.39

26.36

23.66

24.88

27.84

27.62

33.10

38.60

40.87

29.21

37.75

30.61

27.72

37.12

28.98

22.87

23.62

23.69

22.78

21.33

15.41

19.70

18.18

10.17

23.43

21.48

21.74

20.11

30.97

31.22

28.96

13.16

13.22

Depth

$[\mathrm{km}]$

15.0

26.1

25.5

15.0

17.0

15.0

15.0

13.3

491.8

12.0

19.9

19.5

14.7

12.0

15.5

15.7

12.0

15.2

12.0

15.2

14.6

21.1

12.0

23.5

53.5

40.7

17.8

15.6

12.2

18.1

12.0

16.1

15.4

12.0

20.2

18.1

12.0

21.4

14.3

92.4

100.2

122.4

92.5

27.5

216.8

12.0

29.9

12.0

12.6

12.0

28.0

12.0

52.6

52.6

71.2 


\begin{tabular}{llrrrrr} 
& Origin time (UTC) & $\begin{array}{l}\text { Latitude } \\
{\left[{ }^{\circ}\right]}\end{array}$ & $\begin{array}{l}\text { Longitude } \\
\left.{ }^{\circ}\right]\end{array}$ & $\begin{array}{l}\text { Depth } \\
{[\mathrm{km}]}\end{array}$ & $\begin{array}{l}\text { Magnitude } \\
{[\mathrm{Mwc}]}\end{array}$ & Iterations \\
event_101_shift & 2016-08-24 01:36:37 & 42.64 & 13.22 & 12.0 & 6.20 & 65-100 \\
\hline \hline & & & & & & \\
event_102 (D) & 2017-07-20 22:31:17 & 36.80 & 27.62 & 12.0 & 6.60 \\
event_104 (C) & 2017-06-12 12:28:41 & 38.81 & 26.32 & 12.0 & 6.40 \\
event_105 & 2017-03-02 11:07:27 & 37.53 & 38.45 & 17.2 & 5.60 \\
event_106 (B) & 2018-01-04 10:46:12 & 42.60 & 19.82 & 14.7 & 5.20 \\
event_107 (A) & 2017-01-18 10:14:14 & 42.48 & 13.28 & 12.0 & 5.70 \\
event_109 (E) & 2016-05-16 01:45:59 & 28.45 & 34.58 & 15.0 & 5.30
\end{tabular}

\section{$2 \quad$ Adapted event parameters}

Below, we discuss the changes that were made to certain event parameters, including the rationale behind these changes. The actual parameters are given in Table 1 above.

\section{Event 33}

In practically all seismograms, a static shift between observed and synthetic traces is observed (Figure 1). This is independent from epicentral distance and is visible on all components. It is confirmed by the spatial distribution of phase shifts, and the skewed histogram of phase shifts as demonstrated in Figure 2. A time shift of 3 seconds was applied to remove this static shift. As a result, the phase shifts centre around a roughly zero mean (Figure 3).

A time shift is not the only way in which the shift can be explained; however, for the purposes of the inversion (and given the additional constraints given by other events in the area) it is the easiest and most workable explanation.

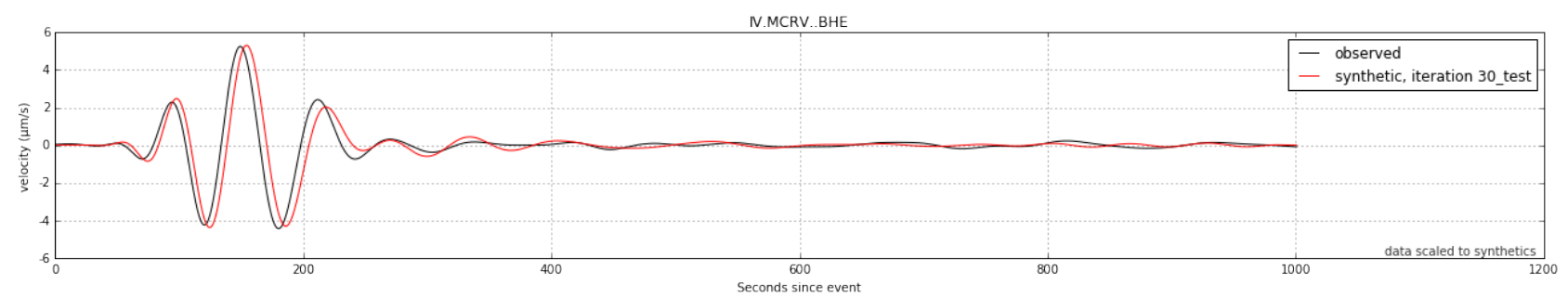

(a) Station IV.MCRV (E component).

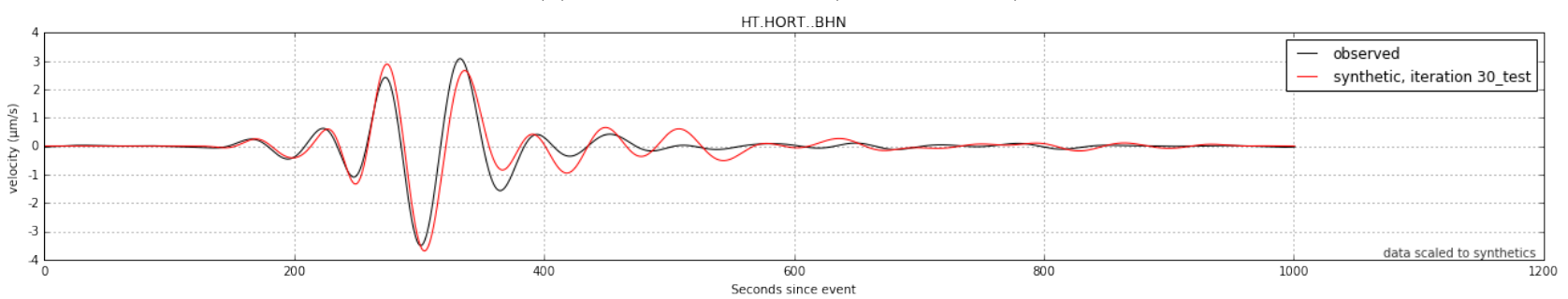

(b) Station HT.HORT (N component).

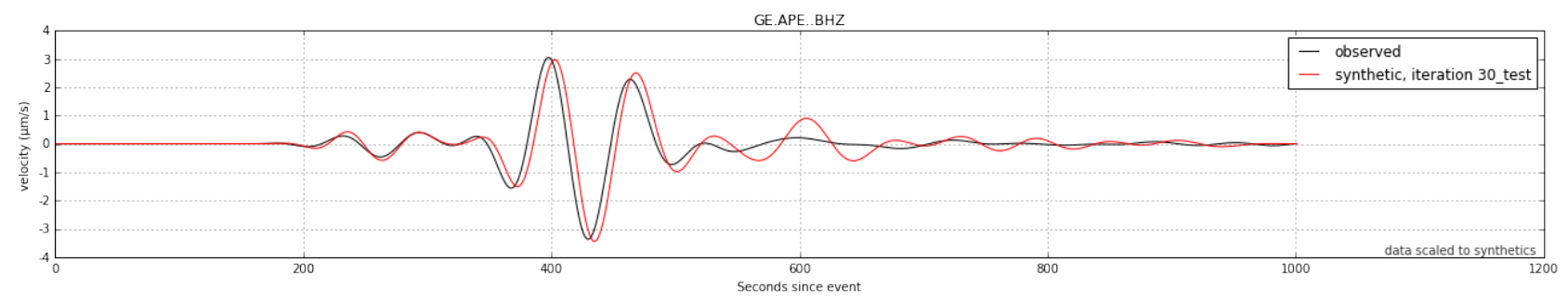

(c) Station GE.APE (Z component).

Figure 1: Seismograms for event 33 (uncorrected) and iteration 30 (55-150 s). 
Event event_33 (2009-04-06 01:32) - 6.3 Mwc - 153 stations with windows $(69.0 \%$ of 221$)$ - iteration 30 test
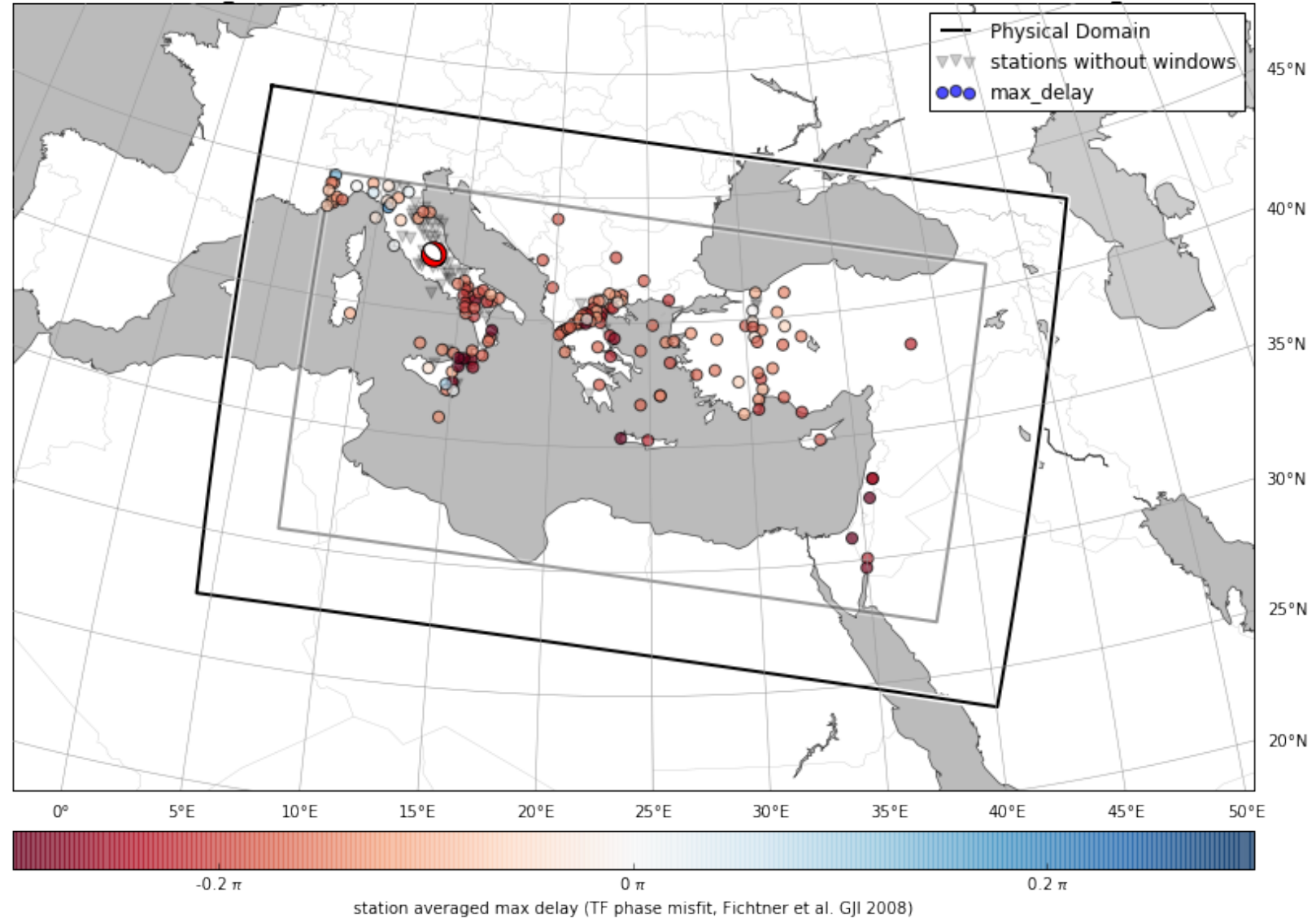

station averaged max delay (TF phase misfit, Fichtner et al. GJI 2008)

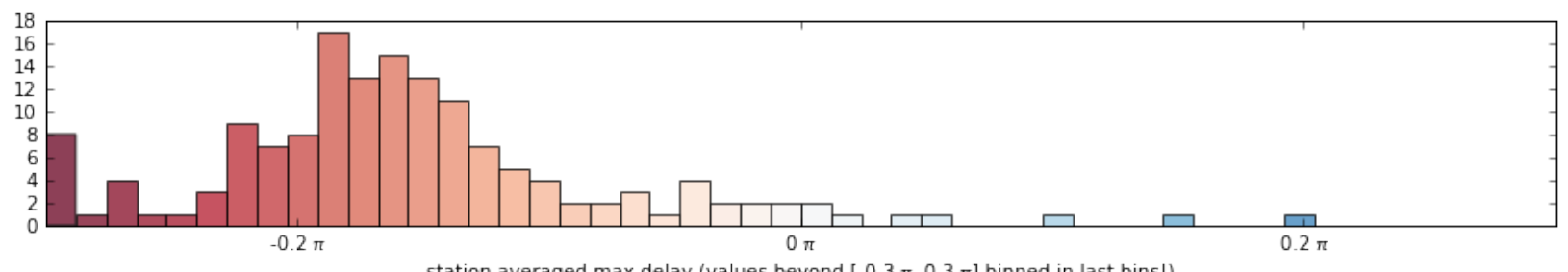

station averaged max delay (values beyond $[-0.3 \pi, 0.3 \pi]$ binned in last bins!)

Figure 2: Original distribution of "max delay" phase shifts for event 33 at iteration 30 (55-150 s). This value is computed for each window as $\max \left(W_{p}\left(\phi-\phi_{\text {obs. }}\right)\right)$ - see Equation 2 in the manuscript. 
Event event_33 (2009-04-06 01:32) - 6.3 Mwc - 153 stations with windows $(69.0 \%$ of 221$)$ - iteration 30 test
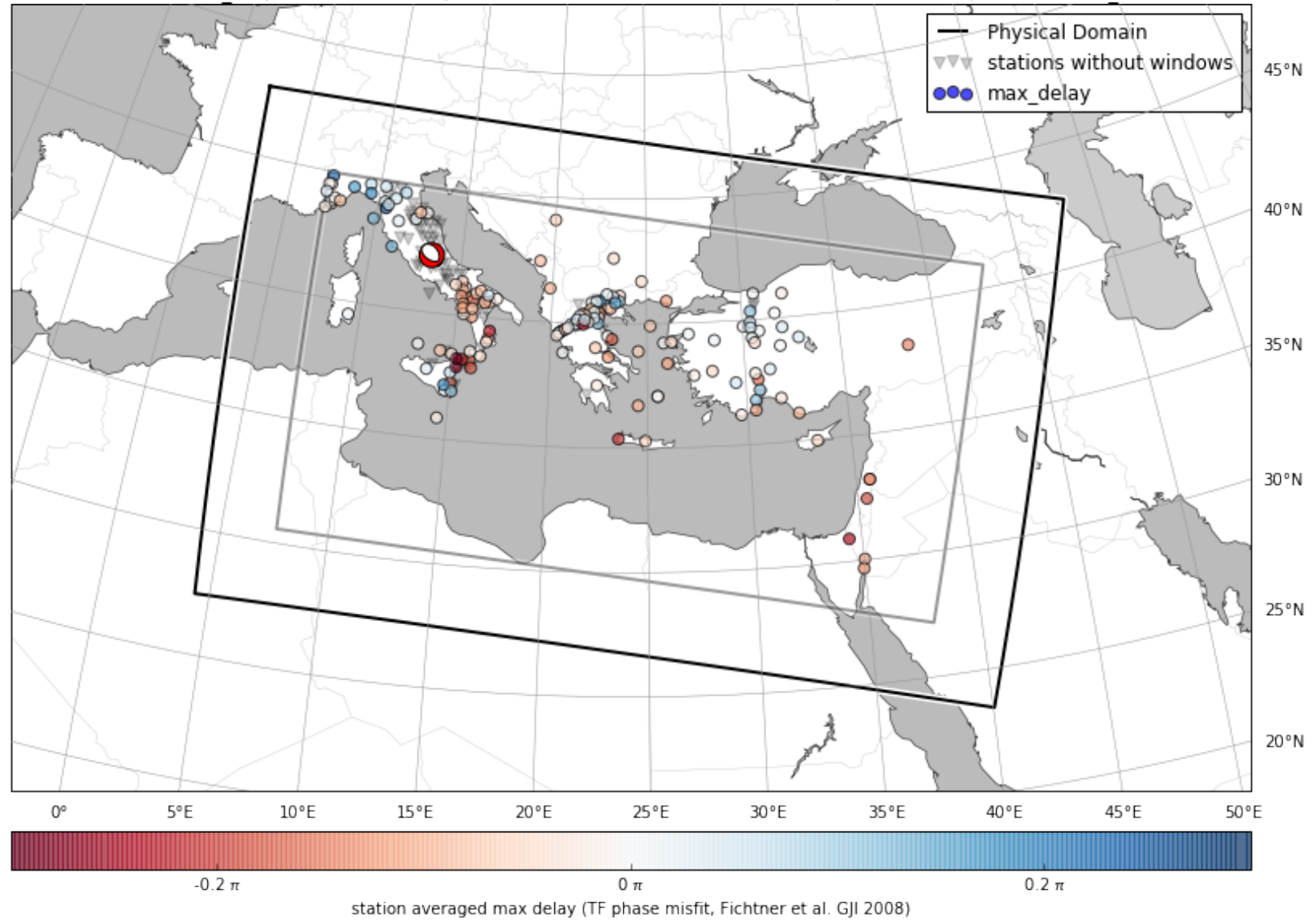

station averaged max delay (TF phase misfit, Fichtner et al. GJI 2008)

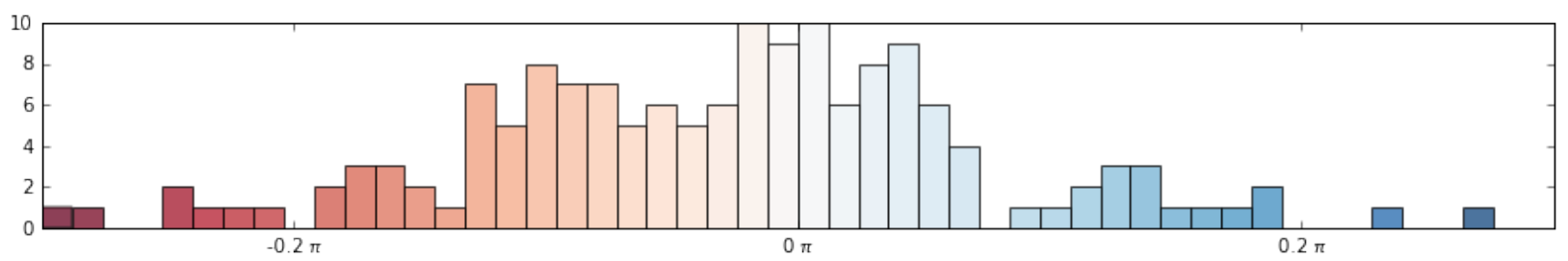

station averaged max delay (values beyond $[-0.3 \pi, 0.3 \pi]$ binned in last bins!)

Figure 3: Distribution of "max delay" phase shifts for event 33 at iteration 30 (55-150 s) after shifting the event origin time by 3 seconds forward. 


\section{Event 38}

Event 38 shows a geographical pattern of phase shifts, with positive shifts towards the north-west and negative shifts towards the south-east (Figure 4). Such phase shifts were not encountered for other events in the same area. This geographical pattern is therefore most easily explained using a small shift of the event towards the north-west. As a result of the applied shift in location, the spatial pattern of space shifts didappears and the histogram of phase shifts centres more around zero (Figure 5). The new location also corresponds more closely with the reported ISC-EHB location (Engdahl et al., 1998; Weston et al., 2018). 
Event event_38 (2012-06-10 12:44) - 6.1 Mwc - 235 stations with windows $(85.0 \%$ of 274$)$ - iteration 65 _0_32s
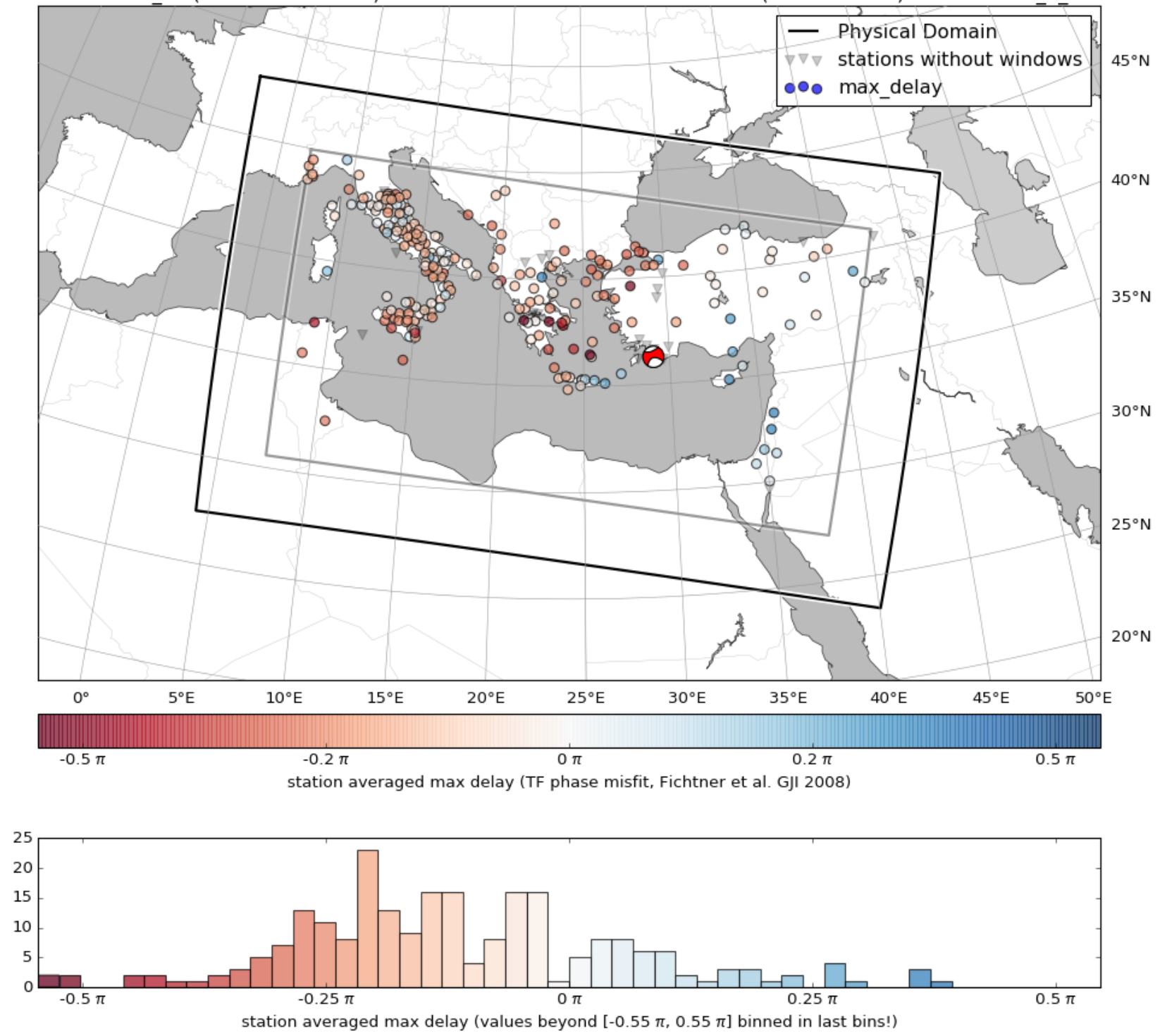

Figure 4: Original distribution of "max delay" phase shifts for event 38 at iteration 65 (32-150 s). 

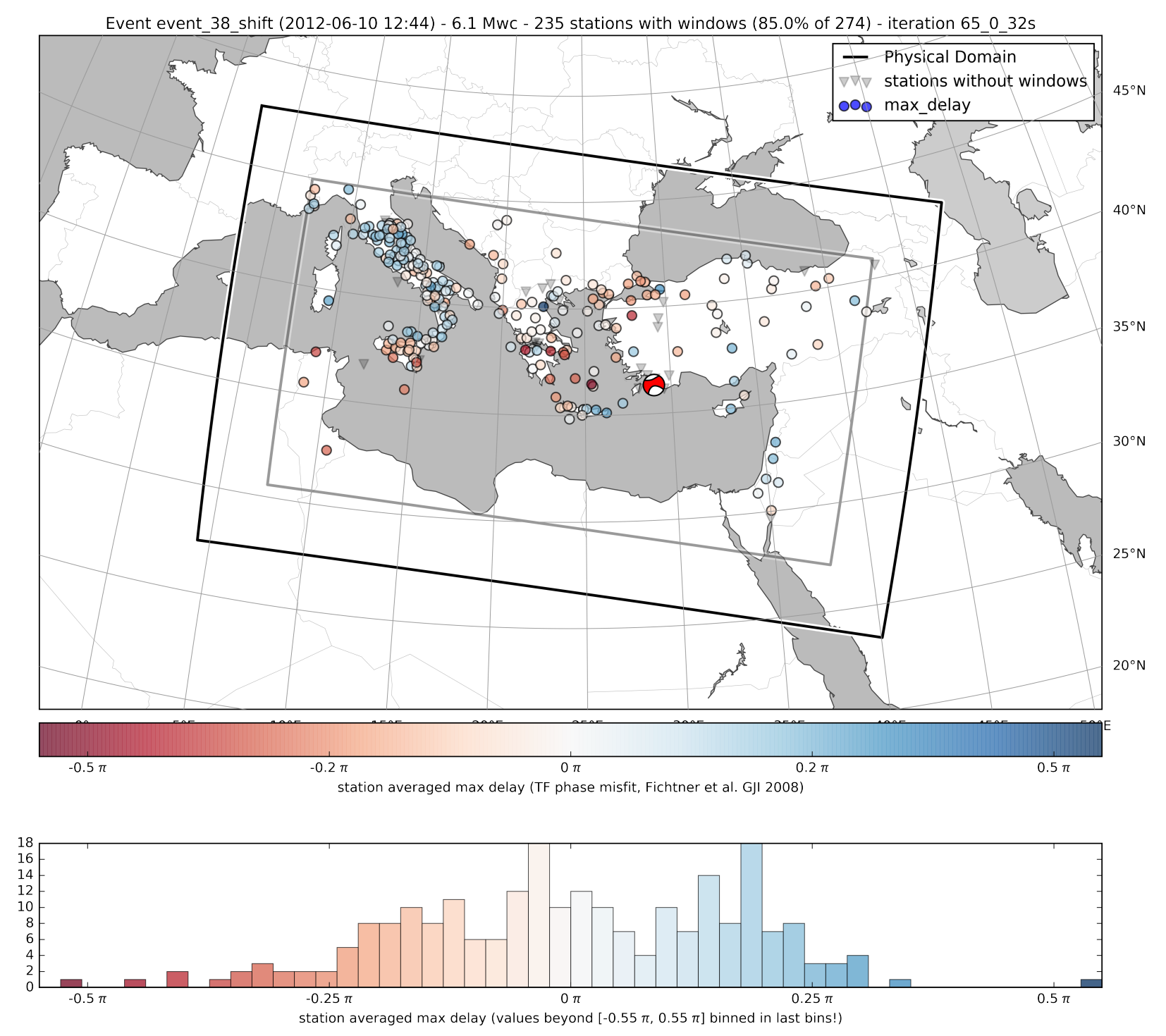

Figure 5: Distribution of "max delay" phase shifts for event 38 at iteration 65 (32-150 s) after shifting the event location towards the north-east (latitude $+0.06^{\circ}$, longitude $-0.06^{\circ}$ ). 


\section{Event 98}

Event 98 shows a strong geographical pattern of phase shifts, with positive shifts towards the south-west and negative shifts towards the north-east (Figure 6). Such phase shifts were not encountered for other events in the same area. This geographical pattern is therefore most easily explained using a relocation of the event towards the north-east. As a result of this, the spatial pattern disappears entirely and the histogram becomes more unimodal and centering around zero (Figure 7). The new location also corresponds more closely with the reported ISC-EHB location (Engdahl et al., 1998; Weston et al., 2018). 
Event event_98 (2013-12-28 15:21) - 5.93 Mwc - 253 stations with windows (79.0\% of 317) - iteration 65_0_32s
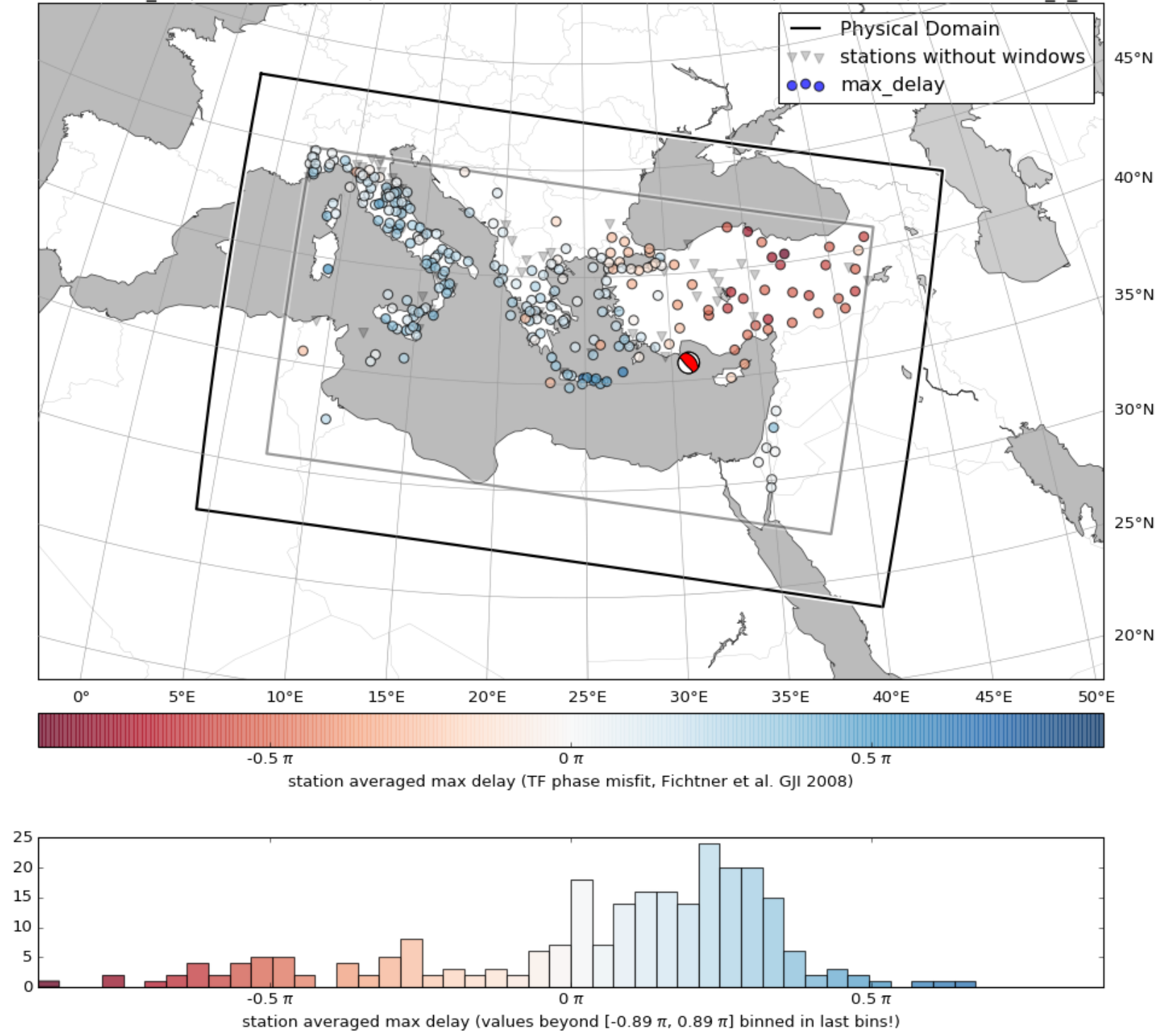

Figure 6: Original distribution of "max delay" phase shifts for event 98 at iteration 65 (32-150 s). 
Event event_98_shift (2013-12-28 15:21) - 5.93 Mwc - 253 stations with windows (79.0\% of 317) - iteration 65_0_32s
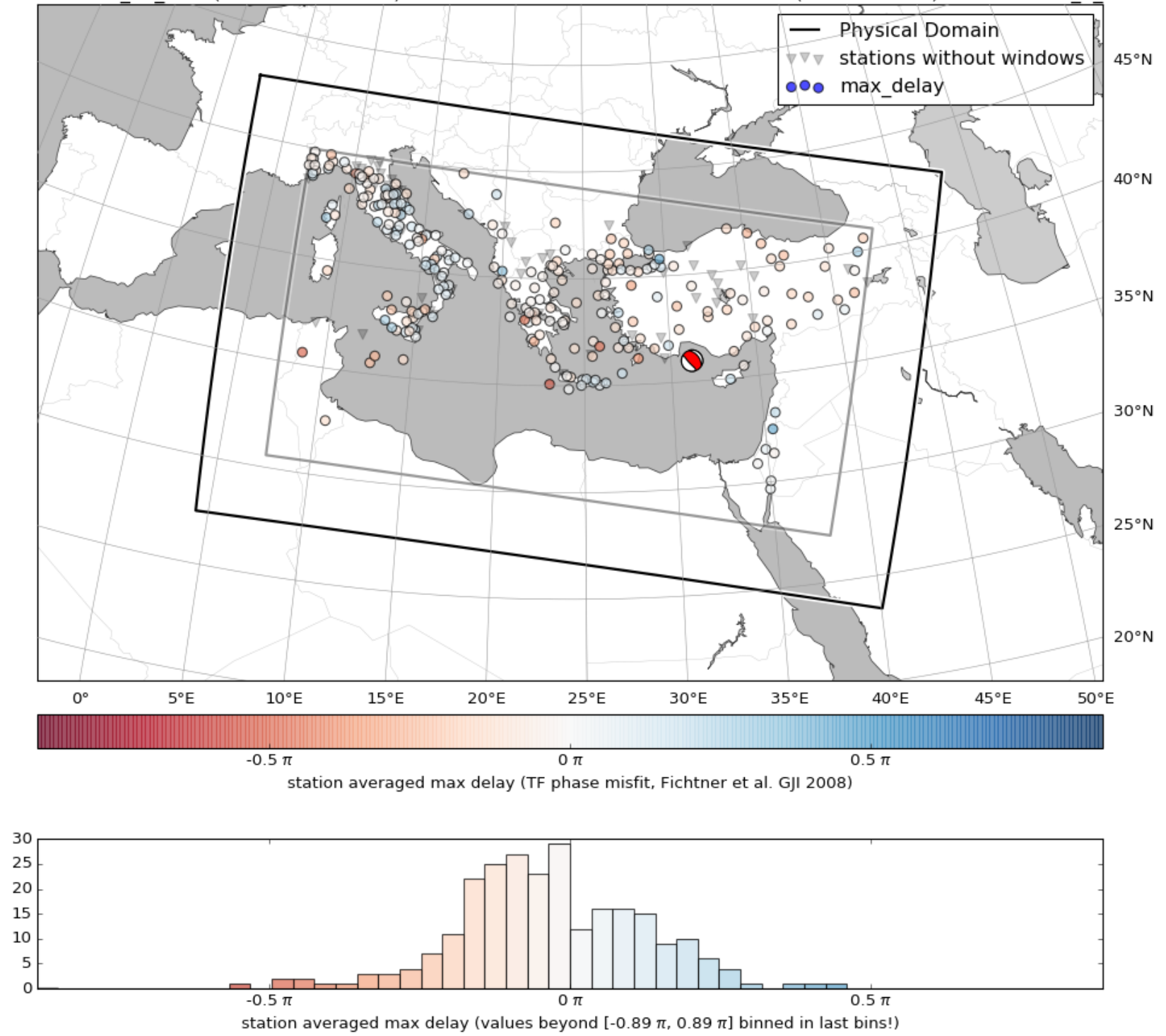

Figure 7: Distribution of "max delay" phase shifts for event 98 at iteration 65 (32-150 s) after shifting the event location towards the north-east (latitude $+0.15^{\circ}$, longitude $+0.25^{\circ}$ ) 


\section{Event 101}

Event 101 fairly consistently showed synthetic waveforms arriving ahead of their corresponding observed data waveforms (Figure 8). This is confirmed by the spatial distribution and histogram of phase shifts, as demonstrated in Figure 9, where the histogram is skewed towards positive phase shifts (i.e. synthetics ahead of observed data). A time shift of 1 second was applied to remove this static shift. As a result, the spatial pattern of phase shifts centred around zero (Figure 3).

As with event 33, a time shift is not the only way in which the shift can be explained; however, for the purposes of the inversion (and given the additional constraints given by other events in the area) it is the easiest and most workable explanation.

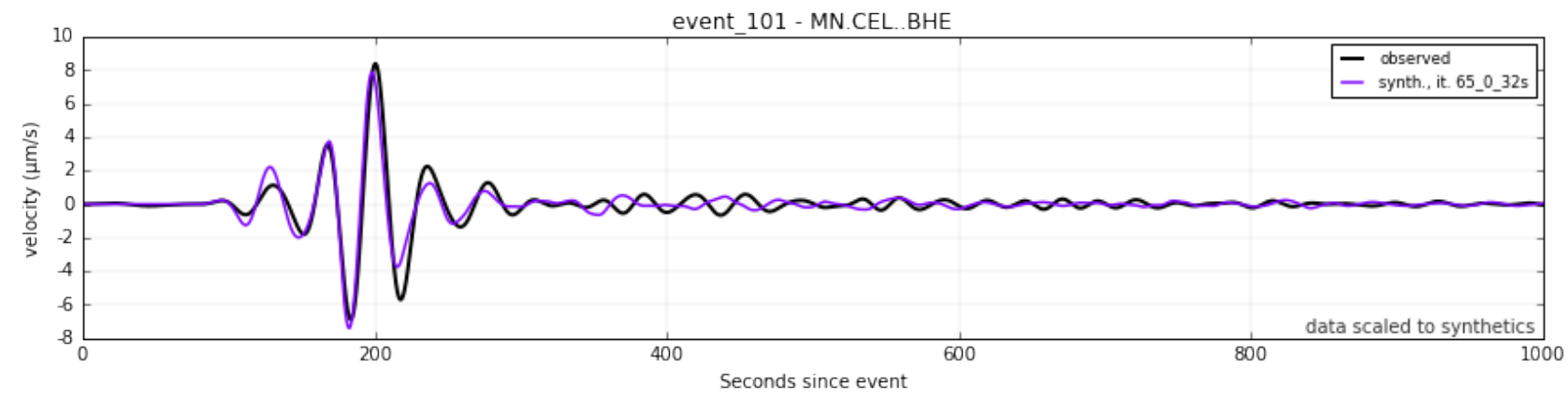

(a) Station MN.CEL (E component).

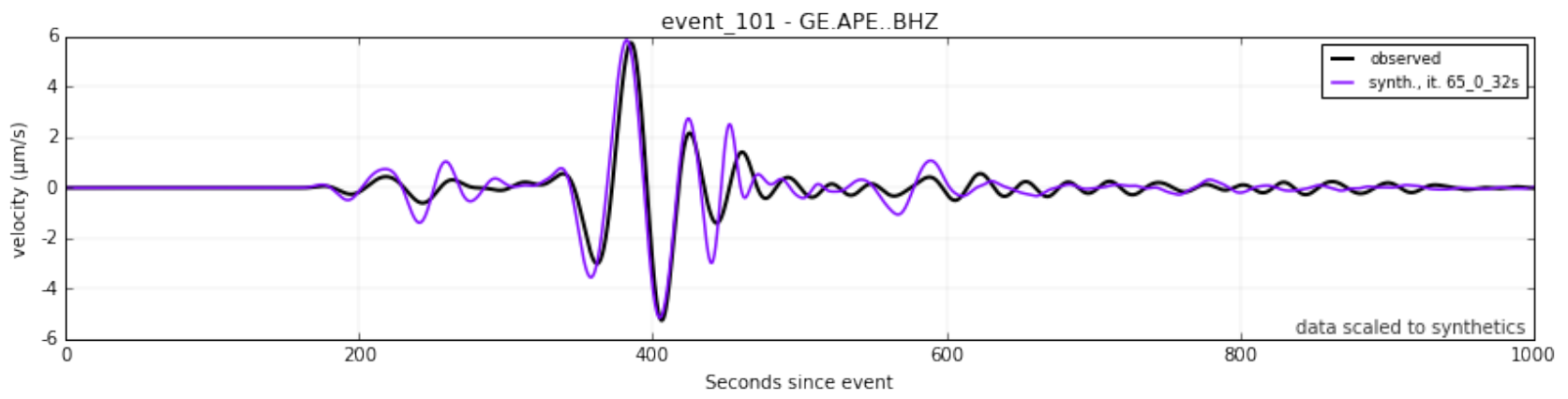

(b) Station GE.APE (Z component).

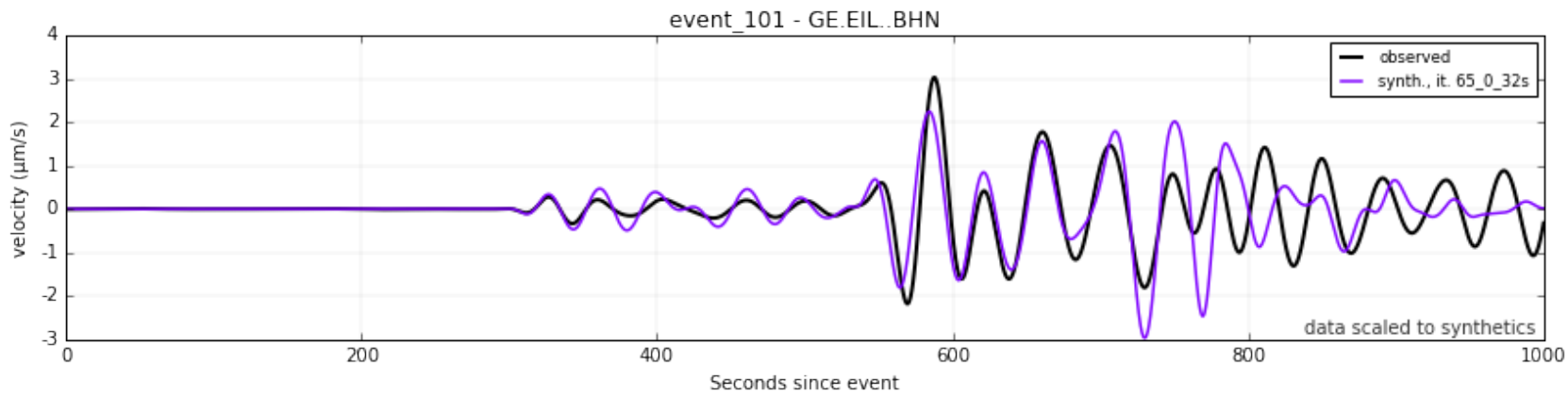

(c) Station GE.EIL (N component).

Figure 8: Seismograms for event 101 (uncorrected) and iteration 65_0_32s (32-150 s). 

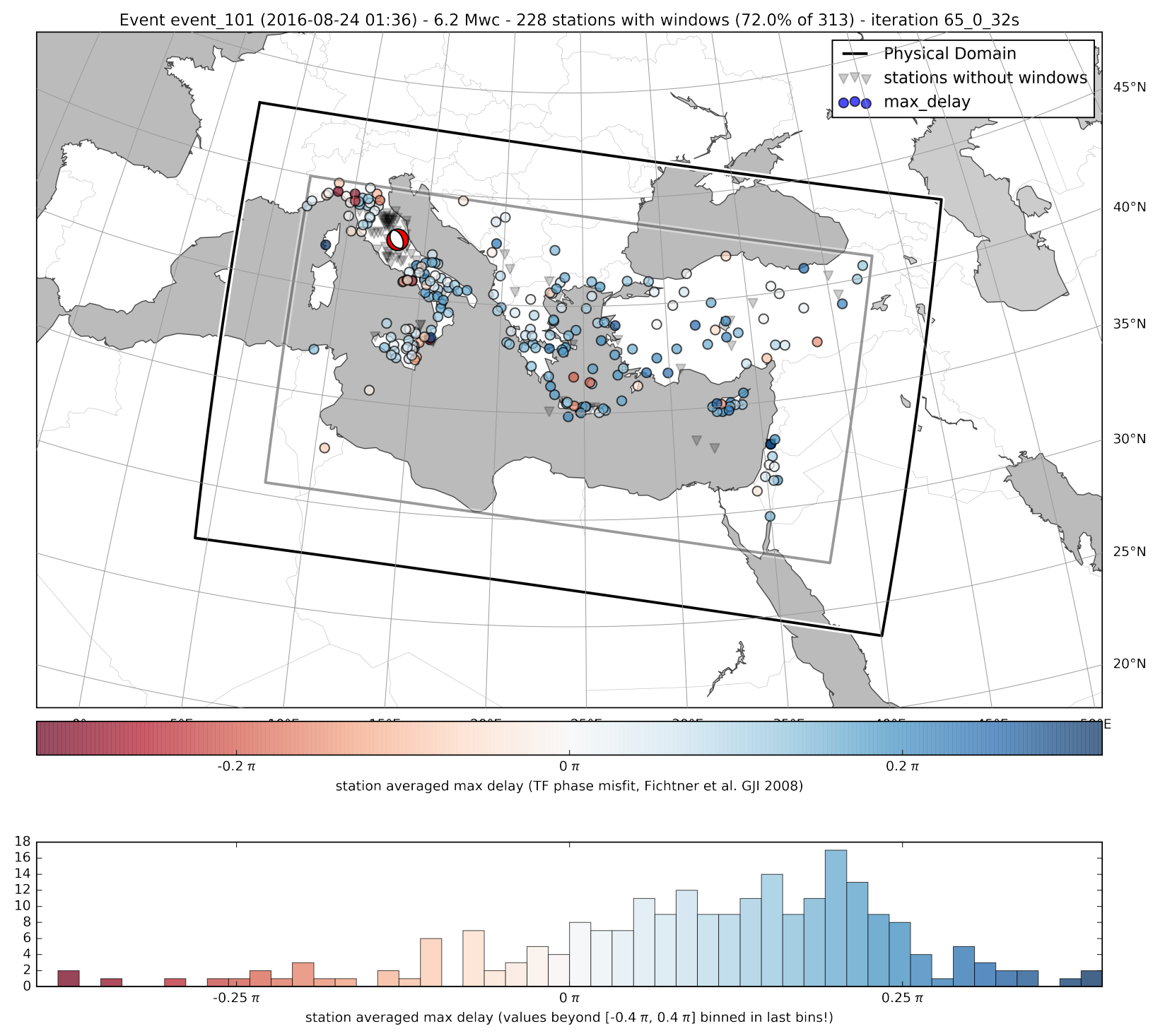

Figure 9: Original distribution of "max delay" phase shifts for event 101 at iteration 65_0_32s (32-150 s). This value is computed for each window as $\max \left(W_{p}\left(\phi-\phi_{\text {obs. }}\right)\right)$ - see Equation 2 in the manuscript. 

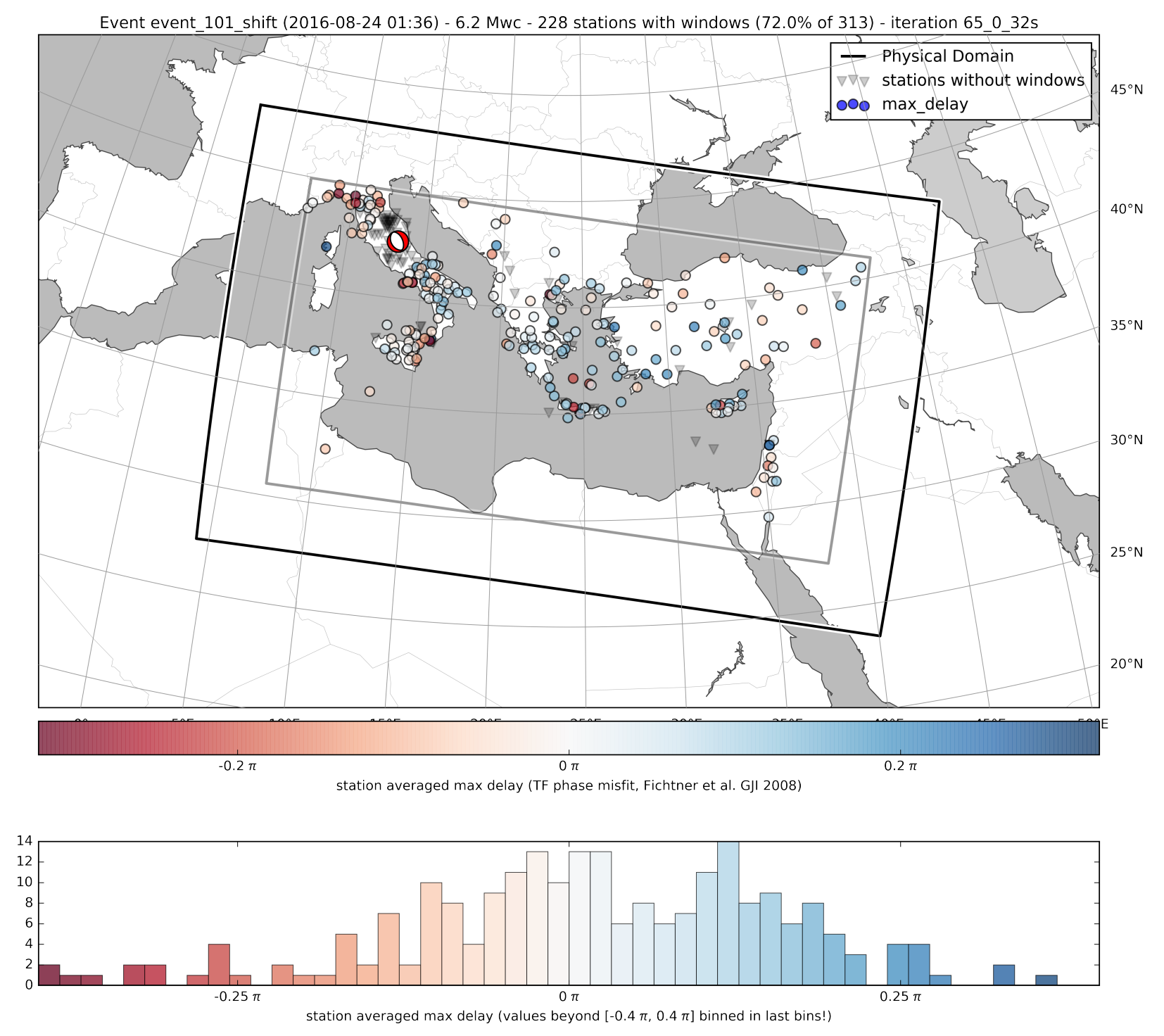

Figure 10: Distribution of "max delay" phase shifts for event 101 at iteration 65_0_32s (32-150 s) after shifting the event origin time by 1 second forward. 


\section{Processing of model updates}

In order to compute a model update, the raw gradients for each model parameter are preprocessed before a descent direction is computed. This is done in order to improve convergence properties of the gradients. Kernels for each event are clipped at the 99th percentile in order to avoid too-strong localisation of updates especially in the source region, and then summed to produce the misfit gradient. The side and bottom edges are set to zero to remove potential boundary effects, and some smoothing is applied. This processing routine is based on experience from previous inversions and some initial experimentation, and the chosen parameters, re-evaluated for every set of iterations, are given in Table 2.

Additionally, at the end of certain sets of iterations, the cumulative model update is processed. These processing parameters are given in italics as the "Post-run" values in Table 2.

\begin{tabular}{|c|c|c|c|c|c|}
\hline$\#$ & Period range & Frequency band & $\begin{array}{l}\text { Number of } \\
\text { iterations }\end{array}$ & $\begin{array}{l}\text { Simulation } \\
\text { length }\end{array}$ & Processing \\
\hline 0 & $100-150 \mathrm{~s}$ & $0.0067-0.01 \mathrm{~Hz}$ & 10 & $1200 \mathrm{~s}$ & cut $3^{\circ}, 100 \mathrm{~km} ; n_{s m}^{h v}=10$ \\
\hline 1 & $80-150 \mathrm{~s}$ & $0.0067-0.0125 \mathrm{~Hz}$ & 10 & $1200 \mathrm{~s}$ & $\begin{array}{l}\text { Post-run: } \text { cut } 4.5^{\circ}, 350 \mathrm{~km} ; n_{s m}^{h}=10, n_{s m}^{v}=50 \\
\text { cut } 3^{\circ}, 100 \mathrm{~km} ; n_{s m}^{h v}=10 \\
\text { Post-run: } \text { cut } 4.5^{\circ}, 370 \mathrm{~km} ; n_{s m}^{h}=3, n_{s m}^{v}=5\end{array}$ \\
\hline 2 & $65-150 \mathrm{~s}$ & $0.0067-0.0154 \mathrm{~Hz}$ & 10 & $1200 \mathrm{~s}$ & cut $4.5^{\circ}, 370 \mathrm{~km} ; n_{s m}^{h v}=10$ \\
\hline 3 & $55-150 \mathrm{~s}$ & $0.0067-0.0182 \mathrm{~Hz}$ & 10 & $1001 \mathrm{~s}$ & $\begin{array}{l}\text { cut } 3^{\circ}, 100 \mathrm{~km} ; n_{s m}^{h v}=10 \\
\text { Post-run: cut } 2.5^{\circ}, 320 \mathrm{~km} ; n_{s m}^{h}=1, n_{s m}^{v}=3\end{array}$ \\
\hline 4 & $46-150 \mathrm{~s}$ & $0.0067-0.0217 \mathrm{~Hz}$ & 10 & $990 \mathrm{~s}$ & cut $2^{\circ}, 300 \mathrm{~km} ; n_{s m}^{h v}=8$ \\
\hline 5 & $38-150 \mathrm{~s}$ & $0.0067-0.0263 \mathrm{~Hz}$ & 10 & $990 \mathrm{~s}$ & $\begin{array}{l}\text { cut } 2^{\circ}, 300 \mathrm{~km} ; n_{s m}^{h v}=8 \\
\text { Post-run: density only: } n_{s m}^{h}=10, n_{s m}^{v}=35\end{array}$ \\
\hline & $38-150 \mathrm{~s}$ & $0.0067-0.0263 \mathrm{~Hz}$ & 5 & $990 \mathrm{~s}$ & $\begin{array}{l}\text { cut } 2^{\circ}, 300 \mathrm{~km} ; n_{s m}^{h}=3, n_{s m}^{v}=15 \\
\text { density: } n_{s m}^{h}=7, n_{s m}^{v}=60\end{array}$ \\
\hline 6 & $32-150 \mathrm{~s}$ & $0.0067-0.0313 \mathrm{~Hz}$ & 15 & $1000 \mathrm{~s}$ & $\begin{array}{l}\text { cut } 2^{\circ}, 300 \mathrm{~km} ; n_{s m}^{h}=3, n_{s m}^{v}=15 \\
\text { density: } n_{s m}^{h}=7, n_{s m}^{v}=60\end{array}$ \\
\hline & $32-150 \mathrm{~s}$ & $0.0067-0.0313 \mathrm{~Hz}$ & 5 & $1000 \mathrm{~s}$ & $\begin{array}{l}\text { cut } 2^{\circ}, 300 \mathrm{~km} ; n_{s m}^{h}=2, n_{s m}^{v}=10 \\
\text { density: } n_{s m}^{h}=4, n_{s m}^{v}=20\end{array}$ \\
\hline 7 & $28-150 \mathrm{~s}$ & $0.0067-0.0357 \mathrm{~Hz}$ & 15 & $900 \mathrm{~s}$ & $\begin{array}{l}\text { cut } 2^{\circ}, 300 \mathrm{~km} ; n_{s m}^{h}=2, n_{s m}^{v}=10 \\
\text { density: } n_{s m}^{h}=4, n_{s m}^{v}=20\end{array}$ \\
\hline
\end{tabular}

Table 2: Overview of inversion choices. The column 'Simulation length' shows the duration of each synthetic earthquake simulation. As frequency increases, the surface wave train becomes more compact (see Figure 3 in the manuscript), so the simulation duration can be shortened. The column 'Processing' indicates the processing applied to the gradients. 'Cut' indicates over which distance the model update is set to zero at the sides (in degrees) or the bottom (in $\mathrm{km}$ ). This is in order to remove boundary reflection issues. ' $n_{s m}$ ' indicates the number of smoothing iterations applied, where superscripts $h, v$ and $h v$ indicate whether this is done in the horizontal direction, in the vertical direction, or simultaneously in the horizontal and vertical directions. In some iterations, additional smoothing was carried out to compensate for smoothing set to values that turned out to be too low. This is indicated in italics. After the first five period bands, separate smoothing for density is introduced, in order to avoid the accumulation of unphysical density values.

\section{References}

Dziewonski, A. M., Chou, T.-A., and Woodhouse, J. H. (1981). Determination of earthquake source parameters from waveform data for studies of global and regional seismicity. Journal of Geophysical Research: Solid Earth, 86(B4):2825-2852.

Ekström, G., Nettles, M., and Dziewonski, A. M. (2012). The global CMT project 2004-2010: centroid moment tensors for 13,017 earthquakes. Phys. Earth Planet. Inter., 200-201:1-9.

Engdahl, E. R., van der Hilst, R., and Buland, R. (1998). Global teleseismic earthquake relocation with improved travel times and procedures for depth determination. Bulletin of the Seismological Society of America, 88(3):722-743.

Weston, J., Engdahl, E. R., Harris, J., DiGiacomo, D., and Storchak, D. A. (2018). ISC-EHB: reconstruction of a robust earthquake data set. Geophysical Journal International, 214(1):474-484. 